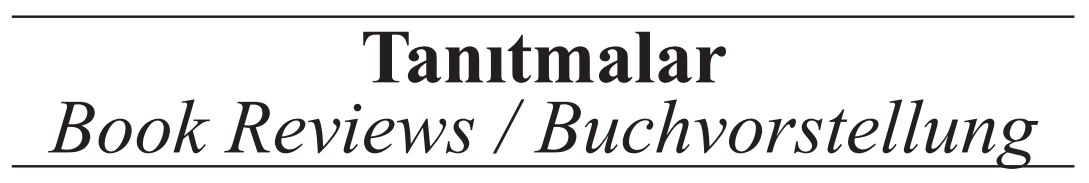



Ahmet Yaşar Ocak Kitabı, Arı Kovanına Çomak Sokmak, Taşra Kökenli Bir Tarihçinin Sıradan Meslek Hayatı (2014). Söy. Haşim Şahin. I. Baskı. İstanbul: Timaş Yayınları.

\section{Murat ALANDAĞLI*}

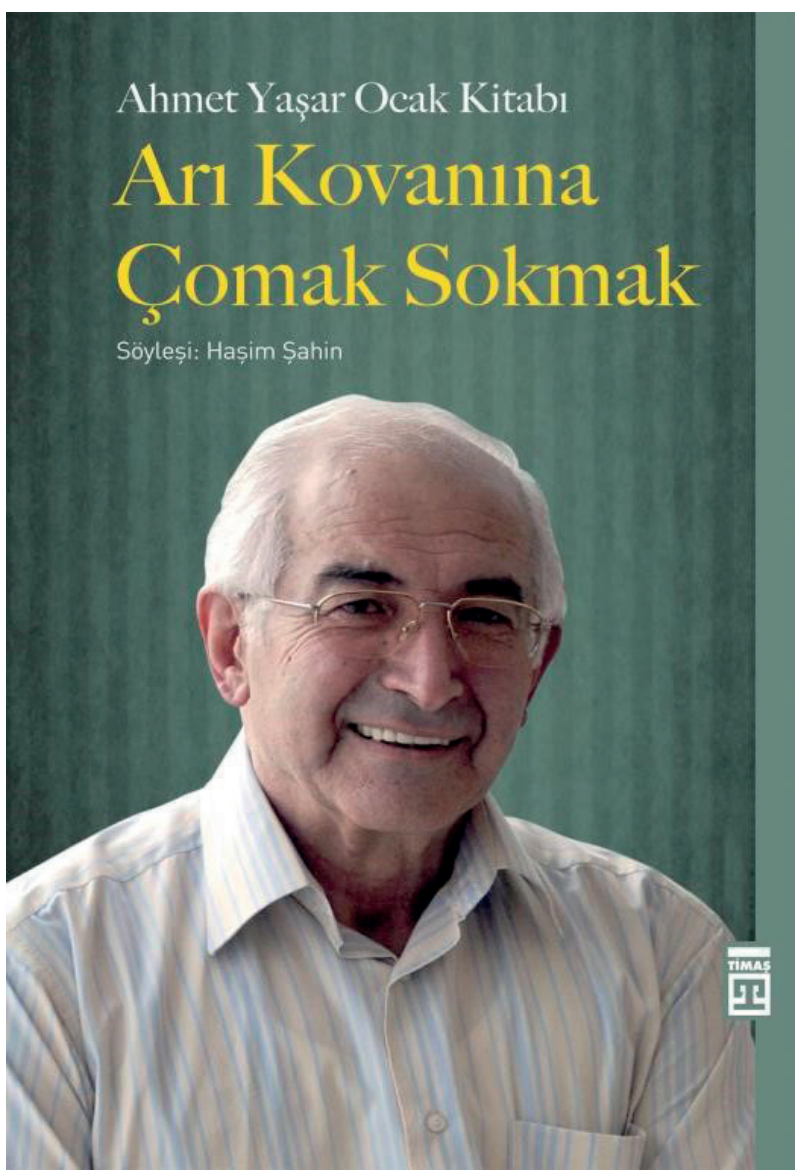

Kitap, dört ana bölüm, albüm ve indeks bölümlerini de kapsayan toplam yirmi bir başlıktan müteşekkil olup 526 sayfadır.

\footnotetext{
* Ö̈̆rr.Gör., Hakkari Üniversitesi. muratalandagli@hakkari.edu.tr.
} 
Kitap, söyleşiyi yapanın Ahmet Yaşar Ocak ile fikri ve bireysel temasına dair girizgâh ile başlamaktadır. Bu bölümde hemen hemen hepimizin hayatımızın farklı dönemlerinde test ettiğimiz beklentilerin veya düşüncelerin tersi bir durumla karşılaşmak, umduğunu bulamamak veya çok çekindiğimiz bir hocamızdan iyi niyetli, zarif bir davranış, karşılama gördügümüzde içine düştüğümüz rahatlığa dair yer yer bireysellik kokan tarif ve izahlara rastlanılmaktadır.

Eserin birinci bölümü, Ahmet Yaşar Ocak'ın ${ }^{1}$ doğum tarihi, doğum yeri, annesi, babası, ailesi, soyuyla ilgili oldukça teferruatlı bilgilerden ibarettir. Yozgat söz konusu olunca Hoca'nın doğup büyüdüğü coğrafyaya ve tarihi derinliğe dair hemen hemen her bölümde pek çok anı, söylence ya da menkıbeye dair anekdotlar dökülür dilinden. Bu nedenle satırlar geçtikçe yöre halkı başta olmak üzere Hoca'nın Çapanoğullarına bakışının aslında bizlerin bildiği veya okuduğundan çok daha farklı olduğu gerçeğiyle yüzleşmekteyiz. Nihayet bir ayan ailesi olmakla birlikte Yozgat'1 imar edenlerin de onlar olduğunu bu sayede öğreniyoruz. Eserde her bölümün ruhuna uygun görsellere de yer verilmiştir. Bu bölümde çocukluk yıllarına ait fotoğraflara rastlanılmaktadır. Eserde zaman zaman Hoca'nın millet olarak tarihe bakışımız ile onu sahiplenişimiz ve muhafazamıza dair çarpıcı tespitlerine tesadüf edilmektedir ${ }^{2}$. Derken eser boyunca kimi zaman ismi geçecek olan çocukluk arkadaşlarına laf gelir dayanır. Sanki dünmüşçesine oynadıkları oyunların kurallarına dair her şey en ince ayrıntısına kadar aklındadır Hoca’nın. Dönem dünyasının imkân verdiği ölçüde gidilen etkinlikler, yaratılan firsatlar, icatlar vs. pek çok aktivite daha çocukluk döneminde ileride donanımlı bir âlim olacağına işaret edercesine sıralanır. Bütün bunlar bir yana aslında Hoca'nın duygusal dünyasına gark olmuş bir imam hatip okulları idaresi, politikası, dünyası, çıkmazı vardır aslında. Hemen hemen her bölümde izlerine tesadüf ettiğimiz bu duygu ile Hoca, adeta ülkemizde özellikle eğitim politikas1 ekseninde bu işte ne kadar başarısız olduğumuzu resmetmek ister. Hemen hemen pek çok akranının şahitlik ettiği çıkmazları hafif bir tebessümle şapkamızı da çıkarmak şartıyla karşılamamıza firsat verir. Bu nedenle bir bakarsınız mahallesinden okula giderken mutlu, mesut çevresinden destek, teşvik gören bir karakter, bazen de gittiği, bitirdiği okulu söylemekten imtina eden bir karakter oluverir. Bu karakter

1 Anlatımda tekdüze bir dil kullanmak adına bundan sonraki atıflarda "Hoca" ibaresi kullanilacaktır.

2 "Bizim millet, tarihine taparcasına bağlı ve sadıktır, ona laf söyletmez ama iş o tarihin bıraktığı eserleri korumaya gelinde sanırım yeryüzünün en hoyrat, en duyarsız ve en tahripkâr milletlerinden biridir.", s. 27. 
farklılığına rağmen imam hatip okullarını, öğrencilerini ve müfredatını över. Zira mevcut başarısını buradaki edinimlerine bağlar. Olağan açıklığıyla bizlerle tanıştırdığ1 her biri farklı dünya, mizah ve yapıdaki hocalarına rağmen o, imam hatip okullarına sadece eğitim değil dini, ahlaki bir hüviyet yükler. Ona göre ülkemizde şu an halisane bir muhafazakâr İslam kalıntısı var ise bu tamamen imam hatipliler sayesindedir. Bu konuda ayrıca zaman zaman başta Çorum, Çankırı ve Kırşehir'den Yozgat'a imam hatipte okumaya gelen öğrencilerin dünyalarına götürür bizi. Öyle ki, bir göz odada binbir sıkıntı ile okumaya gayret eden öğrencilerle karşılaşırız. Belki de bu hususta dönemin hükümeti Demokrat Parti'nin eğitim politikası ile evlatlarını bu okullara gönderen ana-babaların nazarındaki farklılığa değinir. Zira Demokrat Parti, ülkenin din işleri hizmetçisi eksiğini gidermek adına bu okulları açtığını; anne-babaların ise evlatlarının daha ziyade dinlerini, diyanetlerini, kültürlerini çok iyi öğrenip inançlı birer birey olmaları için bu okulları tercih ettiklerinin altını çizerek vurgular ${ }^{3}$.

Öyle veya böyle bitmişs sıkıntılı bir eğitimin akabinde, herkesin elde edemeyeceği bir başarının sonunda Hoca, İstanbul Yüksek İslam Enstitüsü’ne girmeye hak kazanır. Bazen düşünürüz ya özellikle de önemli tercihler ile karşılaştığımızda. Bilindik alıntılar, ifadelerle tespit ve yönlendirmeler kendiliğinden oluverir. Nitekim "senin gibi başarılı bir talebenin imam hatipte işi ne?” şeklinde başlayıp "tıp, hukuk" var iken şeklinde devam eden izahlar, akıl vermeler sıralanır. Bu tayin veya yönlendirme lafları bir tarafa Hoca, Yozgat'tan uzun soluklu ayrılışını ve karşılaştı̆̆ı şehri, soluk bir resim hüviyetiyle bizimle paylaşır. Burada onun entelektüel dünyasına renk katacak pek çok karakter ile tanışılacaktır. Ve elbette İstanbul, tarihsel mekânları, öğrenci yurdu, yurt sohbetleri vb. s1rf ne öğrenebilirim uğruna atılan binlerce adım... Kanımca bu bölümün en dikkat çekici noktası Hoca'nın tarihçilik yöntemi ve metoduna dair kısa ve fakat keskin tespitleridir. Bu nedenle hâlâ fişleme usulüne sadıktır ve yine bu nedenle alıntıların kendi orijinal dillerinde yapılmasını şiddetle tavsiye eder. Yine bu bölümde sinemanın aslında tarih, tarihçi ve tarihçinin konu, mesele tespiti ile irdelemesi açısından ne kadar da önemli bir araç olduğuna şahitlik etmekteyiz ${ }^{5}$. Bugün olduğu gibi o dönemde de ikinci bir dal eğitiminin en azından imam hatip öğrencileri arasında okunması noktasında bir eğilimin olduğu anlaşılıyor. $\mathrm{Bu}$ alışılagelmiş yöntem, uygulama ve prosedür noktasında maalesef yine bilindik bazı bakış acılarına, zorluk çıkarmalara, inkâr ve dışlama gibi kimi uygulamalarla

3 Bk. s. 77.

4 Bk. s. 145.

5 "Hasan Sabbah" filmi örneği, s. 122. 
yüz yüze getirir bizleri. Hayretler içerisinde Allah, Allah! O dönemde de mi varmış? bunlar diye ister istemez söyleniriz.

$\mathrm{Bu}$ arada tarihsel bir meseleye eğilme, bu konu üzerinde yüzeysel veya derinlemesine okumalar yapma, yol gösterici hocaların telkinlerini alma gibi her aşamada imrenerek şahitlik edeceğimiz tarih eğitimi ve okumaların yer aldı̆̆1 bölüme bakmak gerekmektedir. Burada Köprülü, Gölpınarlı, Barkan gibi ülkemiz tarihçiliğinde mihenk taşı olmuş kişilere dair bireysel bazda ortaya konulan olumlu, olumsuz düşünceler hakikaten bazı fikirlerimizi sorgulamamıza firsat vermektedir. Kimi zaman "bir ilahiyatçı", "amatör bir yazar” şeklinde ifade ettiği kişilerden gördüğü olumsuz ve seviyesiz eleştiriler ile hayretle karşıladığ1 akademik camiadan bazı kişilere dair seviyeli yakarışlara da yine bu bölümde tesadüf edilmektedir.

İnsanoğlu olarak hemen hemen hepimizin zaman zaman şaşkınlıkla karşıladığımız, yaşandığı dönemde değil de daha sonraları aklımıza her geldiğinde gülümsediğimiz enteresan olaylarımız vardır. Tarih bölümü ve İstanbul Yüksek İslam Enstitüsü mezuniyetinin akabinde Hoca'nın öğretmen olarak Yozgat'a atanmayı beklerken, Osmaniye'ye atanması gibi... Üstelik bizzat atamayı yapacak kişiye güçlü bir referansla gitmiş olmasına rağmen... Kısa ve fakat özlemle anlatılan bir öğretmenlik döneminin ardından, Hacettepe Üniversitesi’ne geçiş, asistanlık ve yurt dışı eğitim aşamalarının hemen hemen tamamında Hoca'nın akademik ve ilmi vizyonunda adeta bir idol olarak öne çıkan Ercüment Kural ile tanışılacaktır. Hakikaten onun bir öğrenciye yaklaşım, teşvik, tenkit ve elbette mükâfatlandırma ${ }^{6}$ noktasındaki hareketleri, ilgili herkese ders mahiyetindedir. Polatlı Hava Savunma Üssüne ait kavurucu yaz sıcaklığının hâkim olduğu kısa bir askerlik anısını, hâlden anlayan hatta zaman zaman kendilerine karşı mahçup düşen üstlere dair halisane düşünceler izler. Askerliğin bitişi ile yeni bir arayış içerisine girecektir. Bu arayış yurt dışında doktora yapmaktır. Yurt dışında doktora yapılacak ise kiminle ve nerede yapılacaktır. Nihayet Strasbourg'a Melikoff'un yanına gidilecektir. Bu zorlu ve meşakkatli kararın akabinde heyecan ve tedirginlik, endişe dolu bir başka serüven başlar. Acaba Melikoff nasıl kendisini karşılar? Bu tatlı endişeler yerini kısa sürede her ilgilinin arzu edeceği sitemli bir işleyişle devam eden diğer prosedür işlerine bırakır. Kayıt, yurt, kimlik, barınma vs. Artık pek çok kişinin imrenerek okuyacağı doktora ders ve hazırlık süreci başlar. Bu nedenle zaman zaman gidilen yabancı arşivler ile yerli arşiv ve saha, alan gezileri eserde sık sık ön plana çıkar. Çorum, Amasya, Tokat ve Yozgat'1 içine alan çemberdeki seyahatin nedeni de budur.

6 "Ahmet sende tarihçi kafası var, makaleni çok beğendim, bunu hemen yayımla.", s. 180. 
Tespitler, tenkitler okumalar ve nihayet hararetli ve pozitif bir akademik doktora savunmasının akabinde bir soru ve gurur edasıyla yurda dönüş başlar. Burada soru aslında bir cevap mahiyetindedir. Çünkü doktorasını yaptığı ülkede çalışma fırsatı doğmuştur. Bir karar vermesi gerekmektedir. Fakat daha sonra da benzer minvalde almış olduğu ve aynı ciddiyet ve nedenlerle reddettiğine bakılırsa Hoca, bu cevab1 vermek için pek de düşünmemiş olsa gerek diyebiliriz.

Daha sonraları Hoca'nın Hacettepe Üniversitesi'nde kendi deyimiyle adeta kendinin yetişmesine firsat veren ders verme süreci geliyor. Zaman zaman dönemin kaotik ortamının yarattığı ögrenci tipleri ve bunlara karşı yaklaşımına dair anıları eserde beliriyor. Yurt dışında doktora yapmış olmanın vermiş olduğu bir bakış acısıyla öğrencilere sorgulayıcı, araştırıcı bir bakış acısı kazandırmaya gayret ettiğini ve bununda öğrencilerde şaşkınlık yarattığının altı çizilir. Bu arada ülkemizdeki eksiklikler kendisinde büyük bir hayal kırıklığ1 yaratır?

Peki, ama Hoca'nın Türkiye'de tarihçilik, tarih yazımına bakışı nasıldır? Bu soruyu esas alan bölümde Hoca, hem Kemalist hem de muhafazakâr tarihçilerin muhteva ve yöntemlerine ufak bir eleştiri getirir. Bu eleştirileri de bilerek başından beri araştırmayı düşündüğü “Türklerde İslam Alg1sı” mevzusu üzerinden yapar. Ve elbette "Bektaşiliğin Babailiğin devamı mahiyetinde olduğu" yönündeki düşüncesi... $\mathrm{Bu}$ hususta yine hem Alevi hem de Sünni araştırmacıların ideolojik yaklaşımını akademik mizahın el verdiği ölçüde anlatmaya, karşılaştığı zorlukları ifade etmeye çalışır. Konu ideoloji olduğunda ister istemez Kürt meselesi, Alevi-Bektaşiler, imam hatipliler, muhafazakârlar vs. pek çoğu hâlâ maalesef bilindik meselelere değinmeden geçemez. Bunları anlatırken hakikaten olaya pozitif yaklaşmış veya sümenaltı edilmiş çalışmalara değinmeden edemez. Bu nedenle sık sık Gölpınarlı, Köprülü ve Chan, İnalcık, Turan gibi tarihçiler arasında gelgitlere tesadüf edilir.

Son olarak onca çalışmasını üzerine inşa ettiği Alevi-Bektaşilik ve Türklerin İslam’ı algılayış ve uygulayış meselelerine değinilmektedir. Bu konuda Köprülü’nün pek çok tarif ve izahının arkasında olduğunu işaret ederken ayrıca bazı kişi ve çevrelerce "muhbir, ajan” olarak itham edilmesinin vermiş olduğu vicdani rahatsızlı̆̆1 dizelerden anlayabilmekteyiz. O, basit bir izahla Türklerin İslamlaşma sürecini İbn-i Fadlan Seyahatnamesi’ndeki Oğuz Kağan’ın “Tanrımızın karısı var mı?” şeklindeki sorusu

7 “Descartes Türkiye’ye hiç uğramamış...!”, s. 236. 
özelinde anlatmaya gayret eder. Bu bakış acısının ise Osmanlı-Safevi mücadelesine ${ }^{8}$ kadar devam ettiğini fakat bu dönemde keskin ayrılıkların başladığını belirtir. Ayrıca medreseli ve halk kitleleri üzerindeki tespiti de bizce oldukça önemlidir. Nitekim imkânı çerçevesinde elit olarak tarif ettiği kentlerde medreselerde İslam’ı anlama yorumlama ve kavrama firsatına erişmiş olanlar ile bu tazyikin erişemediği taşrada, kırsalda yaşayan halk nazarındaki farklılaşmayı belirgin bir izahla anlatır. Ona göre bugünkü Aleviler, kırsaldaki bu halkların devamıdır.

Kitap; Hoca'nın çocukluk, ilkokul, ortaokul, lise ve yüksekokul ile yüksek lisans ve doktora eğitim-öğretim hayatının akabinde Hacettepe'de başlayıp noktalanan hocalık hayatı ve araştırma sahası, problemlerine dair yukarıda ifade ettiklerimiz ölçüsünde çok derin ve halisane ifadeleri barındıran izah ve ifadeleri içerir. Peki, ama ya onun sık sık ifade ettiği arkadaşları, dostları ve hatta öğrencileri onun hakkında ne düşünür? İşte bu sorunun cevabı ötekiler nazarında Hoca’yı anlamamıza firsat vermektedir. Bu nedenle çocukluk arkadaşı Taha Akyol'un dizelerinde onun daha çocukken tarihe olan ilgisi ve Türkiye tarihçiliğine kazandırdıklarına dair bir dost, arkadaştan ziyade entelektüel bakışı içeren ifadelerine rastlamaktayız. Ve elbette öğrencileri, yani yetişmelerine katkı sağladığı her ne kadar direkt olmasa da "bugün her biri değişik yerlerde, önemli çalışmalar yürüten” şeklinde tarif ettiği ya da cümle aralarına serpiştirdiği öğrencileri... Onun hayatını "okumak, araştırmak ve eser üretmek" şeklinde tarif eden Ö $z^{10}$ ile ilk dönemlerde kendisinden çekindikleri ve derslerde biraz daha gülümsemesi hususunda ricada bulunduklarını hâlen ifadelerinde öğrenci psikolojisinin kokusu hissedilen Özel'in ${ }^{11}$ izahı Hoca'nın kişisel ve akademik hayatına dair canlı örnekleri içerir. Dostların gözüyle Hoca’ya bakışın ifade edildiği bu bölümü, kronolojik yaşam öyküsü, bibliyografyası ve 1930-2014 y1lları aralığında değissik fotoğrafların yer aldığı albümü ve nihayet indeks bölümü takip eder.

8 Bk. s. 394.

9 Gazeteci-Yazar, s. 469-472.

10 Prof. Dr. Mehmet Öz, Hacettepe Üniversitesi, s. 478-480.

11 Doç. Dr. Oktay Özel, Bilkent Üniversitesi, s. 484-487. 
Kitabı okuduğumuzda bireysel veya akademik hayatta dün olduğu gibi bugün de zaman zaman karşılaştığımız zorluk, sıkıntılara dair pek çok benzerlikleri görebilmekteyiz. Eser bizce en başka hiç kimsenin mevcut konum, pozisyonuna öyle güle oynaya gelemeyeceğinin bir ispatı mahiyetindedir. Hele hele bu kişi tarihçiliği meslek olarak seçmişse ve hele de Alevilik ve Bektaşilik gibi çetrefilli, herkesin kendisine göre bir tanım, tarif yaptı̆̆ konuyu problem edinmişse...

İşte bu nedenle kitap sıradan bir insan ehlinin kendi dünyasının tarif ve izahının yanı sıra akademik hayatın da ders verici pek çok yönünü ortaya koyması bakımından şüphesiz kayda değer bir kategoride yer almaktadır. 
Murat ALANDAĞLI

382 Forschungszeitschrift über das Alevitentum und das Bektaschitentum / 2019 / 19 